\title{
Mercury Exposure Levels in Children with Dental Amalgam Fillings
}

\author{
${ }^{1}$ Indu Miriam Varkey, ${ }^{2}$ Rajmohan Shetty, ${ }^{3}$ Amitha Hegde
}

\begin{abstract}
Objectives: Mercury combined with other metals to form solid amalgams has long been used in reconstructive dentistry but its use has been controversial since at least the middle of the 19th century. The exposure and body burden of mercury reviews have consistently stated that there is a deficiency of adequate epidemiological studies addressing this issue. Fish and dental amalgam are two major sources of human exposure to organic $(\mathrm{MeHg})$ and inorganic $\mathrm{Hg}$ respectively.
\end{abstract}

Materials and methods: A total of 150 subjects aged between 9 and 14 years were divided into two groups of 75 subjects each depending on their diet, i.e. seafood or nonseafood consuming. Each category was subdivided into three groups based on number of restorations. Scalp hair and urine samples were collected at baseline and 3 months later to assess the organic and inorganic levels of mercury respectively by atomic absorption spectrophotometer (AAS).

Results: The mean values of urinary mercury (inorganic mercury) in the group of children with restorations were $1.5915 \mu \mathrm{g} / \mathrm{l}$ as compared to $0.0130 \mu \mathrm{g} / \mathrm{l}$ in the groups with no amalgam restorations ( $p<0.001$ ) (Wilcoxon sign rank test and paired t-test). The hair mercury levels (organic mercury) varied significantly between the fish-eating group and nonfish-eating group, the average values being $1.03 \mu \mathrm{g} / \mathrm{l}$ and $0.84 \mu \mathrm{g} / \mathrm{l}$ respectively ( $p<0.001)$ (Mann-Whitney U-test and paired t-test).

Conclusion and significance: The notion about the mercury being released from the amalgam restorations as a sole exposure source needs to be put to a rest, as environmental factors collectively overpower the exposure levels from restorations alone.

Keywords: Amalgam, Mercury levels, Hair sample, Urine sample, Toxicity.

How to cite this article: Varkey IM, Shetty R, Hegde A. Mercury Exposure Levels in Children with Dental Amalgam Fillings. Int J Clin Pediatr Dent 2014;7(3):180-185.

\footnotetext{
${ }^{1}$ Former Postgraduate Student, ${ }^{2}$ Professor

${ }^{3}$ Professor and Head

${ }^{1-3}$ Department of Pedodontics and Preventive Dentistry, AB Shetty Memorial Institute of Dental Sciences, Mangalore Karnataka, India
}

Corresponding Author: Indu Miriam Varkey, Former Postgraduate Student, Department of Pedodontics and Preventive Dentistry, AB Shetty Memorial Institute of Dental Sciences, Mangalore, Karnataka, India, Phone: 9619486124 e-mail: induvarkey08@gmail.com

\section{Source of support: Nil}

\section{Conflict of interest: None}

\section{INTRODUCTION}

The use of mercury and its combinations with other metals in dentistry dates back to centuries ago. Dental amalgam contains about $50 \%$ mercury, with the remainder mainly silver. Although alternative dental materials are increasingly available for posterior fillings, amalgam has advantages that maintain its popularity as a filling material. These include relatively low cost, increased durability, and less sensitivity to clinical technique than other materials. ${ }^{1}$ The use of mercury in dentistry has been controversial since at least the middle of the 19th century. This controversy has intensified lately, because of techniques showing mercury to be continuously released from dental amalgam fillings. ${ }^{2}$

Mercury is a metallic element that occurs naturally in the environment. There are three primary categories of mercury and its compounds: elemental mercury, which may occur in both liquid and gaseous states, inorganic mercury compounds and organic mercury compounds (MeHg).

$\mathrm{MeHg}$ is present as a result of the methylation of inorganic $\mathrm{Hg}$ by microorganisms, usually present in sediments. It undergoes a remarkable biomagnification process and accumulates in the fish muscle tissues of long-lived predatory species, such as sharks in ocean waters. ${ }^{3}$

Elemental mercury is the main form of mercury released into the air as a vapor by natural processes. Elemental mercury can be oxidized by the hydrogen peroxide-catalase pathway in the body to its inorganic divalent form. Elemental mercury $\left(\mathrm{Hg}^{0}\right)$ emitted to the atmosphere is converted to soluble forms, deposited into soil and water, and methylated to methyl mercury (MeHg). Fish and dental amalgam are two major sources of human exposure to organic ( $\mathrm{MeHg}$ ) and inorganic mercury respectively.

The exposure from dental amalgam occurs mainly by inhalation of elemental mercury evaporating from the filling. ${ }^{4}$ Mercury vapor absorption occurs through the lungs, with about $80 \%$ rapidly entering the blood stream. Following distribution by blood circulation, mercury can 
enter and remain in certain tissues like the central nervous system and the kidneys for longer periods of time.

The following factors have been listed as variables affecting the release of mercury from, amalgam restorations: number of teeth, number of surfaces, baseline mercury release, magnification factors, such as eating and tooth brushing, oral breathing habits, nose-mouth breathing ratio, inspiration-expiration ratio, swallowing, inhalation absorption, ingestion absorption, body weight. ${ }^{5}$

Some mercury species, such as methyl mercury accumulate at higher concentrations in hair, making them relatively easy to measure. Mercury remains stable for long periods in hair, making it easy to transport and store. Mercury also has a longer half life in hair, hence, useful for evaluating exposures that occurred months earlier. ${ }^{6}$

No conformational studies of the past provide consistent results of mercury toxicity, ${ }^{7,8}$ hence, this study was carried out to investigate the organic and inorganic levels of mercury among the pediatric age group.

\section{MATERIALS AND METHODS}

One hundred and fifty subjects either males or females, of the age group ranging from 9 to 14 years, belonging to both fish eating and nonfish eating categories and living in the South Kanara district, Karnataka, India, were included in the study. Informed consent was obtained from each of the subjects. They were healthy subjects with no known prior or existing restorations. They were included if fully erupted permanent maxillary and mandibular first molars on both right and left sides were present with at least one being carious. The carious lesions being treated belonged to the class I genre of Black's classification which is moderately deep. Subjects who were uncooperative or those with underlying physician diagnosed psychological, behavioral, neurological, immunosuppressive or renal disease were excluded.

They were divided into two equal groups of $75 \mathrm{sub}-$ jects each depending on their diet, i.e sea food consuming or nonseafood consuming subjects. The subjects belonging to the 'sea food consuming' category were those who have been eating sea food thrice weekly for at least the past 2 months. The 'nonseafood consuming' category consisted of pure vegetarians. Once the subjects were included into the study group, their diet was restricted to three servings of sea food per week.

The 75 subjects in the 'sea food consuming' category were subdivided into three groups as follows:

- Group 1: Subjects requiring 1 to 2 restorations $(\mathrm{n}=25)$

- Group 2: Subjects requiring 3 to 4 restorations $(n=25)$

- Group 3: Control group with no restorations $(\mathrm{n}=25)$
Further, the subjects under the 'nonseafood consuming' category were subdivided into three groups as follows:

- Group 4: Subjects requiring 1 to 2 restorations $(\mathrm{n}=25)$

- Group 5: Subjects requiring 3 to 4 restorations $(n=25)$

- Group 6: Control group with no restorations $(\mathrm{n}=25)$

The dental materials used in this trial were universally accepted tooth filling materials (Dentsply). All dental treatments met the existing standards of care.

Scalp hair samples were collected from each of the subjects belonging to all groups to assess the organic levels of mercury. A single strand of hair was collected on the day of examination for baseline values and then 3 months later and was subjected to the atomic absorption spectrophotometer (AAS). ${ }^{9}$

Urine samples were collected from the control group subjects and before the start of any restorative procedure in the study group subjects for baseline values and 3 months post filling in all the study groups and control groups to assess the inorganic levels of mercury. The urine sample ( $10 \mathrm{ml}$, morning mid stream sample) collected from each subject of study and control groups was subjected to the cold vapor technique together with atomic absorption spectrophotometer (CVAAS) for analysis. ${ }^{10}$ The samples were digested before analysis with nitric acid to a homogenous solution. This would release bound mercury as $\mathrm{Hg}^{2+}$ from protein sulfur complexes.

Participants and dentists could not be blinded to treatment assignment, but all those collecting outcome data or analyzing the specimens at the laboratory were blinded to the child's treatment assignments.

Comparisons were made between the amalgam treatment group and the control group with and without seafood consumption in terms of the urinary mercury concentration (for inorganic and elemental mercury levels) ${ }^{11}$ and scalp hair mercury concentration (for organic mercury levels). ${ }^{12}$

\section{STATISTICAL ANALYSIS}

The various observations were subjected to statistical analysis as follows:

1. Variations in mercury levels before and after restorations-Wilcoxon sign rank test.

2. Variations within each group at baseline and 3 months later in urine and hair samples paired t-test.

3. Comparison of mercury levels between fish eaters and nonfish eaters Mann-Whitney U-test.

4. Comparison of mercury levels in children having restorations and control groups with no restorationsMann-Whitney U-test.

5. Comparison of mercury levels between boys and girls Mann-Whitney U-test. 


\section{RESULTS}

Table 1 indicates the variation in mercury levels in urine and hair samples between baseline and 3 months later analyzed using the Wilcoxon sign rank test. The increased levels of mercury were found to be statistically significant ( $p<0.001)$ in both hair and urine samples after 3 months from baseline values.

Table 2 shows the variation within each group at baseline and 3 months later in urine samples analyzed using the paired $\mathrm{t}$-test. The values increased significantly $(p<0.001)$ in all the study groups, i.e. the groups with amalgam restorations, whereas the slight increase seen in control groups were not significant $(p=0.007)$. Group 4 showed an increase from $0.21 \mu \mathrm{g} / \mathrm{l}$ to $1.62 \mu \mathrm{g} / \mathrm{l}$, and group 5 showed a higher elevation of mercury levels from 0.21 $\mu \mathrm{g} / 1$ to $2.10 \mu \mathrm{g} / \mathrm{l}$, showing a correlation between increased levels of mercury to increased surfaces of restorations.

Table 3 shows the variations in mercury levels of hair between each of the six subgroups in this study evaluated using the paired $t$-test. The values increased significantly in all the fish eating groups $(\mathrm{p}<0.001)$, whereas the levels did not increase significantly in the nonfish eating groups $(\mathrm{p}=0.001)$.

Table 4 compares the differences in levels of mercury in hair and urine samples between the fish eaters and nonfish eaters, using the Mann-Whitney U-test. The difference in mercury levels in urine of fish eaters was 1.11 $\mu \mathrm{g} / \mathrm{l}$ and of nonfish eaters was $1.26 \mu \mathrm{g} / \mathrm{l}$. This difference was not statistically significant $(\mathrm{p}=0.181)$. The difference in mercury levels in hair of the fish eaters was $1.03 \mu \mathrm{g} / 1$ and $0.08 \mu \mathrm{g} / \mathrm{l}$ in nonfish eaters, the difference between the two groups being statistically significant $(p<0.001)$.

Table 5 compares the differences in levels of mercury in hair and urine samples between the study groups (with restorations) and the control groups (without restorations) done using the Mann-Whitney U-test. The difference in mercury levels in urine of the study groups (i.e. with restoration) was $1.59 \mu \mathrm{g} / \mathrm{l}$ and of the control groups (i.e. without restoration) was $0.01 \mu \mathrm{g} / \mathrm{l}$. This difference was statistically significant $(\mathrm{p}<0.001)$. The difference in mercury levels in hair of the study groups (i.e. with restoration) was $0.32 \mu \mathrm{g} / 1$ and $0.43 \mu \mathrm{g} / \mathrm{l}$ in the control groups (i.e. without restoration ), the difference between the two groups not being statistically significant $(\mathrm{p}=0.333)$.

\section{DISCUSSION}

Dental amalgams, commonly known as 'silver fillings,' contain mercury, silver, tin, copper and zinc. ${ }^{13,14}$ Liquid elemental mercury $(\mathrm{Hg})$ when added to the other ingredients produce a mass that is moldable enough to be forced into the prepared cavity. Manual pressure is used to squeeze out the excess of $\mathrm{Hg}$. Curing occurs in about a day with the final mass containing 45 to $50 \% \mathrm{Hg}$ by weight. $^{15}$

Dental amalgams have long been believed to contribute little to the body burden of mercury. This is because the elemental form of mercury is rapidly consumed in the setting reaction of the restoration. But, research now

Table 1: Variation in mercury levels in urine and hair samples between baseline and 3 months later $(\mu \mathrm{g} / \mathrm{l})$ - Wilcoxon sign rank test

\begin{tabular}{|c|c|c|c|c|c|c|c|c|c|c|}
\hline & \multicolumn{2}{|r|}{$N$} & \multirow[t]{2}{*}{ Minimum } & \multirow[t]{2}{*}{ Maximum } & \multicolumn{3}{|c|}{ Percentiles } & \multirow[t]{2}{*}{ Mean rank } & \multirow[t]{2}{*}{$Z$} & \multirow{2}{*}{$\begin{array}{l}\text { Asymp. sig. } \\
\text { (2-tailed) }\end{array}$} \\
\hline & Valid & Missing & & & 25 & Median & 75 & & & \\
\hline Urine baseline & 150 & 0 & 0.0190 & 0.6720 & 0.12800 & 0.21450 & 0.325250 & 24.42 & -10.075 & $<0.001$ \\
\hline Urine $3 \mathrm{M}$ & 150 & 0 & 0.0410 & 2.7730 & 0.27250 & 1.4015 & 1.93000 & 79.94 & & \\
\hline Hair baseline & 150 & 0 & 0.0140 & 1.9720 & 0.25475 & 0.74050 & 1.00850 & 49.83 & -10.063 & $<0.001$ \\
\hline Hair 3 M & 150 & 0 & 0.0290 & 4.5600 & 0.35075 & 1.2220 & 2.16750 & 76.57 & & \\
\hline
\end{tabular}

Table 2: Variation within each group at baseline and, 3 months later, in urine samples $(\mu \mathrm{g} / 1)$ — paired t-test

\begin{tabular}{|c|c|c|c|c|c|c|c|c|c|c|}
\hline & & Valid & Min. & Max. & 25 & Median & 75 & $\begin{array}{l}\text { Mean } \\
\text { rank }\end{array}$ & $Z$ & $p$-value \\
\hline \multirow{2}{*}{$\begin{array}{l}\text { Fish eating with } 1 / 2 \\
\text { restorations (group 1) }\end{array}$} & Urine baseline & 25 & 0.019 & 0.672 & 0.128 & 0.314 & 0.43 & 0.00 & $-4.372^{b}$ & $<0.001$ \\
\hline & Urine $3 \mathrm{M}$ & 25 & 1.009 & 2.458 & 1.243 & 1.523 & 1.707 & 13.00 & & \\
\hline \multirow{2}{*}{$\begin{array}{l}\text { Fish eating with } 3 \text { or more } \\
\text { restorations (group } 2 \text { ) }\end{array}$} & Urine baseline & 25 & 0.125 & 0.567 & 0.191 & 0.325 & 0.4645 & 0.00 & $-4.372^{b}$ & $<0.001$ \\
\hline & Urine $3 \mathrm{M}$ & 25 & 1.224 & 2.682 & 1.6315 & 2.089 & 2.3905 & 13.00 & & \\
\hline \multirow{2}{*}{$\begin{array}{l}\text { Nonfish eating with } 1 / 2 \\
\text { restorations (group } 4 \text { ) }\end{array}$} & Urine baseline & 25 & 0.021 & 0.623 & 0.1275 & 0.21 & 0.249 & 0.00 & $-4.372^{\mathrm{b}}$ & $<0.001$ \\
\hline & Urine $3 \mathrm{M}$ & 25 & 1.008 & 2.512 & 1.225 & 1.625 & 1.971 & 13.00 & & \\
\hline \multirow{2}{*}{$\begin{array}{l}\text { Nonfish eating with } 3 \text { or } \\
\text { more restorations (group 5) }\end{array}$} & Urine baseline & 25 & 0.026 & 0.526 & 0.14 & 0.214 & 0.351 & 0.00 & $-4.372^{b}$ & $<0.001$ \\
\hline & Urine $3 \mathrm{M}$ & 25 & 1.052 & 2.773 & 1.876 & 2.108 & 2.438 & 13.00 & & \\
\hline \multirow{2}{*}{$\begin{array}{l}\text { Fish eating control group } \\
\text { (group 3) }\end{array}$} & Urine baseline & 25 & 0.052 & 0.381 & 0.094 & 0.171 & 0.274 & 18.00 & $-1.952^{b}$ & 0.051 \\
\hline & Urine $3 \mathrm{M}$ & 25 & 0.041 & 0.393 & 0.126 & 0.186 & 0.2745 & 11.75 & & \\
\hline \multirow{2}{*}{$\begin{array}{l}\text { Nonfish eating control group } \\
\text { (group 6) }\end{array}$} & Urine baseline & 25 & 0.026 & 0.415 & 0.098 & 0.167 & 0.2655 & 9.14 & $-2.651^{b}$ & 0.007 \\
\hline & Urine $3 \mathrm{M}$ & 25 & 0.08 & 0.476 & 0.127 & 0.206 & 0.2625 & 14.50 & & \\
\hline
\end{tabular}

${ }^{\mathrm{b}}$ Positive rank 
Mercury Exposure Levels in Children with Dental Amalgam Fillings

shows that amalgam is not entirely chemically stable after curing. In contrast to earlier studies, recent evidence suggests that amalgam in the oral environment constantly releases small quantities of cytotoxic corrosion products and $\mathrm{Hg}$ vapor. ${ }^{16,17}$ The $\mathrm{Hg}$ vapor levels are greatly increased by mildly abrasive action, such as chewing gum and brushing, and ingestion of hot beverages. ${ }^{18}$ The current point of controversy is whether or not the levels released are great enough to be hazardous to the health of the patient.

No large studies have been completed that examine the effects of mercury exposure from dental amalgam fillings in children. This study was carried out among children ranging from 9 to 14 years. These young children are particularly vulnerable to the effects of mercury because their brains are still developing, and greater surface area in the lungs relative to their body weight causing increased inhalation. Also, elemental mercury is heavier than air and higher concentrations may be seen at lower levels near the child's breathing zone. ${ }^{19}$
Mercury is a naturally occurring element and exists in three forms: organic, inorganic and elemental ${ }^{5}$ and this study analyses all three exposure forms in children.

\section{Organic Mercury Level Assessment}

Organic/methylmercury which is discarded by industries into the water bodies concentrates in tissues of fish and other sea creatures and moves up the food chain. Fish and marine mammals are the dominant sources, contributing up to 70 to $90 \%$ of the total mercury. Larger the fish, more the concentration of mercury in them. The intake of mercury depends not only on the level of mercury in fish but also the amount consumed. In lieu of the above, fish eating and a nonfish eating population was selected for comparisons in this study.

Sample collected to assess organic mercury was hair ${ }^{6}$ mainly because mercury has a longer half life in hair and remains relatively stable. In our study, children of the age group 9 to 14 years were chosen confirming no hair treatments to have been done. An occipital hair sample

Table 3: Variation within each group at baseline and, 3 months later, in hair samples $(\mu \mathrm{g} / \mathrm{l})$ - paired t-test

\begin{tabular}{|c|c|c|c|c|c|c|c|c|c|c|}
\hline & \multirow{2}{*}{$\frac{N}{\text { Valid }}$} & \multirow[t]{2}{*}{ Min. } & \multirow[t]{2}{*}{ Max. } & \multicolumn{3}{|c|}{ Percentiles } & \multirow{2}{*}{$\begin{array}{l}\text { Mean } \\
\text { rank }\end{array}$} & \multirow[t]{2}{*}{$Z$} & \multirow[t]{2}{*}{$p$-value } \\
\hline & & & & & 25 & Median & 75 & & & \\
\hline Fish eating with $1 / 2$ restorations & Hair baseline & 25 & 0.714 & 1.647 & 0.83 & 0.902 & 1.3765 & 0.00 & $-4.373^{\mathrm{b}}$ & $<0.001$ \\
\hline (Group 1) & Hair $3 \mathrm{M}$ & 25 & 1.212 & 2.301 & 1.374 & 1.428 & 2.0123 & 13.00 & & \\
\hline Fish eating with 3 or more restorations & Hair baseline & 25 & 0.712 & 1.972 & 0.92 & 1.032 & 1.8275 & 0.00 & $-4.373^{b}$ & $<0.001$ \\
\hline Grou & Hair & 25 & 1.701 & 3.06 & 1.255 & 1.357 & 2.677 & 13.00 & & \\
\hline Nonfish eating with $1 / 2$ restorations & Hair baseline & 25 & 0.021 & 1.325 & 0.1035 & 0.174 & 0.379 & 11.00 & $-3.285^{b}$ & 0.001 \\
\hline (Group 4) & Hair $3 \mathrm{M}$ & 25 & 0.029 & 1.532 & 0.1475 & 0.221 & 0.5685 & 12.27 & & \\
\hline Nonfish eatin & Hair b & 25 & 0.11 & 0.916 & 0.2145 & 0.314 & 0.4 & 23.50 & $-3.108^{b}$ & 0.001 \\
\hline (Group 5) & Hair $3 \mathrm{M}$ & 25 & 0.1019 & 1.006 & 0.311 & 0.424 & 0.6685 & 12.09 & & \\
\hline Fish eating & Hair baseline & 25 & 0.1042 & 1.676 & 0.759 & 0.881 & 0.982 & 0.00 & $-4.372^{b}$ & $<0.001$ \\
\hline (Group 3) & Hair $3 \mathrm{M}$ & 25 & 0.42 & 1.701 & 0.82 & 1.065 & 1.491 & 13.00 & & \\
\hline Nonfish eating & Hair baseline & 25 & 0.014 & 1.116 & 0.136 & 0.256 & 0.35 & 17.00 & $-3.115^{b}$ & 0.001 \\
\hline (Group 6) & Hair $3 \mathrm{M}$ & 25 & 0.043 & 1.025 & 0.2595 & 0.332 & 0.444 & 12.83 & & \\
\hline
\end{tabular}

${ }^{\mathrm{b}}$ Positive rank

Table 4: Comparison of difference in the mercury levels between fish eaters and nonfish eaters $(\mu \mathrm{g} / \mathrm{l})$ - Mann-Whitney U-test

\begin{tabular}{|c|c|c|c|c|c|c|c|c|c|c|c|}
\hline & & Valid & Min. & Max. & $\begin{array}{l}25 \\
\text { percentile }\end{array}$ & Median & $\begin{array}{l}75 \\
\text { percentile }\end{array}$ & $\begin{array}{l}\text { Mean } \\
\text { rank }\end{array}$ & $\begin{array}{l}\text { Mann- } \\
\text { Whitney } \\
\text { U-test }\end{array}$ & $Z$ & $\begin{array}{l}\text { Asymp. sig } \\
\text { (2-tailed) }\end{array}$ \\
\hline \multirow{2}{*}{$\begin{array}{l}\text { Differences in } \\
\text { urine levels }\end{array}$} & Fish eaters & 75 & -0.05 & 2.44 & 0.0150 & 1.1140 & 1.5900 & 70.75 & 2456.500 & -1.338 & 0.181 \\
\hline & Nonfish eaters & 75 & -0.08 & 2.51 & 0.0620 & 1.2630 & 1.7960 & 80.25 & & & \\
\hline \multirow{2}{*}{$\begin{array}{l}\text { Differences in } \\
\text { hair levels }\end{array}$} & Fish eaters & 75 & 0.19 & 3.35 & 0.5510 & 1.0310 & 1.4887 & 112.15 & 64.000 & -10.331 & $<0.001$ \\
\hline & Nonfish eaters & 75 & -0.53 & 0.52 & 0.350 & 0.0840 & 0.1560 & 38.85 & & & \\
\hline
\end{tabular}

Table 5: Comparison of difference in the mercury levels in the study groups (with restorations) and control groups (without restorations) $(\mu \mathrm{g} / \mathrm{l})$-Mann-Whitney U-test

\begin{tabular}{|c|c|c|c|c|c|c|c|c|c|c|c|}
\hline & \multirow{2}{*}{$\begin{array}{l}N \\
\text { Valid }\end{array}$} & \multirow[t]{2}{*}{ Min. } & \multirow[t]{2}{*}{ Max. } & \multicolumn{3}{|c|}{ Percentiles } & \multirow{2}{*}{$\begin{array}{l}\text { Mean } \\
\text { ranks }\end{array}$} & \multirow{2}{*}{$\begin{array}{l}\text { Mann- } \\
\text { Whitney } \\
\text { U-test }\end{array}$} & \multirow[t]{2}{*}{$Z$} & \multirow{2}{*}{$\begin{array}{l}\text { Asymp. sig. } \\
\text { (2-tailed) }\end{array}$} \\
\hline & & & & & 25 & Median & 75 & & & & \\
\hline \multirow{2}{*}{$\begin{array}{l}\text { Differences in } \\
\text { urine levels }\end{array}$} & Restoration present & 100 & 0.40 & 2.51 & 1.186 & 1.5915 & 1.845 & 100.50 & 0.000 & -9.967 & $<0.001$ \\
\hline & Restoration absent & 50 & -0.08 & 0.16 & 0.0003 & 0.0130 & 0.0468 & 25.50 & & & \\
\hline \multirow{2}{*}{$\begin{array}{l}\text { Differences in } \\
\text { hair levels }\end{array}$} & Restoration present & 100 & -0.53 & 3.35 & 0.0890 & 0.3260 & 0.8653 & 73.07 & 2257.00 & -0.969 & 0.333 \\
\hline & Restoration absent & 50 & -0.90 & 2.78 & 0.0690 & 0.4395 & 1.451 & 80.36 & & & \\
\hline
\end{tabular}


was collected at baseline and, 3 months later, half life of $\mathrm{MeHg}$ being around 70 days.

The difference in organic mercury levels in hair samples in our study varied significantly between the fish eating group and nonfish eating group, the average values being $1.03 \mu \mathrm{g} / 1$ and $0.084 \mu \mathrm{g} / 1$ respectively $(\mathrm{p}<$ 0.001). This is in accordance with studies by Salehi et al, ${ }^{9}$ Fakour et $\mathrm{al}^{12}$ and Kruzikova et $\mathrm{al}^{20}$ who showed the increased concentrations of hair mercury due to seafood consumption. The levels were significantly increased in all the fish eating groups irrespective of the presence or absence of restorations, thus, stating the increase to be from the organic mercury only.

Intake of fish and fish products, averaged over months or weeks, results in an average daily absorption of methylmercury variously estimated to be between 2 and 4.7 $\mu \mathrm{g}$ mercury as quoted in literature by Levy $\mathrm{M}$ et $\mathrm{al}^{21}$ and Suzuk $\mathrm{T}^{22}$ in studies done in children, which is in accordance with our study.

The FDA (USA) quotes the maximum allowable concentration of methylmercury to be no more than $1 \mathrm{ppm}(1 \mathrm{mg} / \mathrm{l})$ or alternatively they state that a safe intake would be $0.1 \mu \mathrm{g} / \mathrm{kg}$ body weight. ${ }^{23}$ In India, studies done by Ramamurthy (1979) and Bhattacharya and Sarkar (1996), give max permissible limits as $0.5 \mathrm{ppm} .{ }^{24}$ In our study, the minimum and maximum values observed in the fish eating groups were $0.19 \mu \mathrm{g} / \mathrm{l}$ and $3.3 \mu \mathrm{g} / \mathrm{l}$ which is well within the permissible limits for organic levels of mercury in children. ${ }^{21,22}$

\section{Inorganic/Elemental Mercury}

Dental fillings made with mercury amalgam can be a source of human exposure to elemental mercury vapors for many population. Amalgam surfaces release mercury vapor into the mouth and lung, depending upon the number of amalgam fillings and other factors, the estimated average daily absorption of mercury vapor from dental fillings varies between 3 and $17 \mu \mathrm{g}$ mercury. ${ }^{24}$ Thus, amalgam restoration groups were used as study groups in this study to measure exposure levels as other sources of exposure are highly variable and would not be standardized.

The presence of mercury in urine ${ }^{25}$ generally represents recent exposure to inorganic and/or elemental mercury, and collection is noninvasive. However, inorganic mercury can accumulate in the kidney and slowly get excreted through the urine, thus, also capable of representing exposures to elemental mercury and/or inorganic mercury that occurred sometime in the past. ${ }^{26,27}$ Nicolae $A^{28}$ and Doddes ${ }^{5}$ also state that the most common way to measure mercury exposure is through urine samples, since its fairly easy to collect these samples. Hence, in our study, midmorning samples of urine were collected at baseline and, 3 months later, half life being around 66 days.

The mercury levels in urine increased significantly in all the groups with amalgam restorations from baseline values to a 3-month follow-up period, irrespective of the consumption of seafood. The mean values of urinary mercury in the group of children with restorations were $1.59 \mu \mathrm{g} / \mathrm{l}$ as compared to $0.01 \mu \mathrm{g} / \mathrm{l}$ in the groups with no amalgam restorations $(\mathrm{p}<0.001)$. A proportional increase in urinary mercury levels has been observed with an increase in number of restorations in our study, adhering to the principles of Olsson and Bergman. ${ }^{29}$

The findings thus demonstrate a strong positive association between urinary mercury concentration and number of amalgam surfaces as seen in others studies by Guzzi G, ${ }^{30}$ Woods JS et al ${ }^{10}$ and Xibiao Ye. ${ }^{31}$

Our study is also in agreement with other studies wherein the levels of mercury in urine increased subsequently after amalgam restorations, specifically in children. The New England trial shows median value of 1.5 $\mu \mathrm{g} / \mathrm{l} \pm 1.2,{ }^{10}$ and Levy et $\mathrm{ll}^{21}$ showed that, in children aged 4 to 8 years old, children with amalgam fillings (1.412 microg $\mathrm{Hg} / \mathrm{g}$ ) had significantly higher urinary Hg levels than children without amalgams (0.436 microg Hg/g).

Studies on exposed humans do not provide sufficient information to derive acceptable intakes for inorganic mercury compounds; therefore, based on no adverse effects and lowest adverse effects in medium- and longterm animal experiments, ATSDR and IPCS derived a guidance value of $0.2 \mu \mathrm{g} / \mathrm{kg}$ body weight per day for inorganic mercury compounds. The values obtained in our study stays well clear off the maximum permissible limits.

Notably, we observed a constant but quantifiable urinary mercury excretion among children in this study who did not receive amalgam restorations. This most likely represents the systemic uptake of mercury from food, air, or other environmental sources like industries, broken instruments, medications, etc.

The observations in this study imply that the level of mercury exposure from all sources including amalgam restorations did not exceed the capacity for elimination via the urinary excretion in these subjects.

The New England trial ${ }^{31}$ did a follow-up for 7 years in children with amalgam restorations and revealed that the inorganic levels of mercury in urine peaked after 3 years and reduced to nil after 7 years. This has been an exclusive longitudinal study done in children and, as per their findings, we could also expect the inorganic levels to come down to baseline values after a few years. Thus, inorganic levels of mercury does not seem to pose 
a threat as much as organic levels observed in hair which remains fairly constant. Thus, in a coastal area like the South Kanara region in Karnataka, India, where the present study was undertaken, the residents who consume fish on a regular basis could probably be at a higher risk of organic toxicity than an inorganic one. Hence, should amalgam restorations be done in a subject who consumes fish on a regular basis still remains questionable, due to inadequate long-term evaluations of individual mercury levels. Thus, longitudinal studies in the same group of children needs to be carried out to evaluate variations in exposure levels with time.

\section{REFERENCES}

1. Bates MN, Fawcett J, Garett N, Cutress T, Kjellstrom T. Health effects of dental amalgam exposure: a retrospective cohort study. Int J Epidemiol 2004;33(4):894-902.

2. Mutter J, Naumann J, Sadaghiani C, Walach H, Drasch G. Amalgam studies: disregarding basic principles of mercury toxicity. Int J Hyg Environ Health 2005;208(5):435-436.

3. Ping Li, Feng X, Qiu G. Methylmercury exposure and health effects from rice and fish consumption: a review. Int J Environ Res Public Health 2010;7:2666-2691.

4. Barregard L, Trachtenberg F, McKinlay S. Renal effects of dental amalgam in children: the New England children's amalgam trial. Environ Health Perspect 2008 March;116(3): 394-399.

5. Doddes JE. The amalgam controversy. JADA 2001;132(3): 348-356.

6. Nuttall KL. Interpreting hair mercury levels in individual patients. Annals of Clinical and Laboratory Science 2006; 36(3):248-261.

7. Weiner JA, Nylander M, Berglund F. Does mercury from amalgam restorations constitute a health hazard? Sci Total Environ 1990;99:1-22.

8. Cutress TW, Major IA, Pakomov GN, editors. Dental amalgam and human health, current situation: a New Zealand review. Dental Amalgam and Alternative Direct Restorative: Materials. Geneva: World Health Organization 1997. p. 63-71.

9. Salehi Z, Esmaili-Sari A. Hair mercury levels in pregnant women in Mahshahr, Iran: fish consumption as a determinant of exposure. Sci Total Environ 2010 Sep 15;408(20):4848-4854.

10. Woods JS, Martin MD, Leroux BG, DeRouen TA, Leitão JG, Bernardo MF, Luis HS, Simmonds PL, Kushleika JV, Huang Y. The contribution of dental amalgam to urinary mercury excretion in children. Environ Health Perspect 2007 Oct;115(10):1527-1531.

11. Bellinger DC, Trachtenberg F, Zhang A, Tavares M, Daniel D, McKinlay S. Dental amalgam and psychosocial status: The New England Children's Amalgam Trial. JDR 2008 May; 87(5):470-474.

12. Fakour H, Sari EA, Zayeri F. Mercury exposure assessment in Iranian women's hair of a port town with respect to fish consumption and amalgam fillings. Sci Total Environ 2010 March;408(7):1538-1543.

13. Gelband $H$. The science and politics of dental amalgam. Int J Technol Assess Health Care 1998;14(1):123-134.
14. Anusavice KJ. Phillips' Science of Dental Materials. 11th ed. Philadelphia: WB Saunders and CO; 2011. p. 495-496.

15. Wolff M, Osborne IW, Hanson AL. Mercury toxicity and dental amalgam. Neuro Toxicology 1983;4(3):201-204.

16. Abraham JE, Svare CW, Frank CWo. The effects of dental amalgam' restorations on blood mercury levels. J Dent Res 1984 Jan;63(1):71-73.

17. Friberg L, Kullman L, Lind B. Central nervous system in relation to amalgam filling. Kvicksilver Lakartidningen 1986; 83(7):519-522.

18. Patterson JE, Weissberg BG, Dennison PJ. Mercury in human breath from dental amalgams. Bull Environ Contam Toxicol 1985 Apr;34(4):459-468.

19. ATSDR (Agency for Toxic Substances and Disease Registry), US. Department of health and human services guidelines. Section of environmental epidemiology and toxicology 2008.

20. Kruzikova K, Modra H, Kensova R, Skocovska B, Wlasow T, Svoboda T, Svobodova Z. Mercury in human hair as an indicator of the fish consumption. Neuro Endocrinol Lett 2008 Oct;29(5):675-679.

21. Levy M, Schwartz S, Dijak M, Weber JP, Tardif R, Rouah F. Childhood urine mercury excretion: dental amalgam and fish consumption as exposure factors. Environmental Research 2004;94(3):283-290.

22. Suzuki T, Hongo T, Abe T, Matsuo N, Inoue N. Urinary mercury level in Japanese schoolchildren: influence of dental amalgam fillings and fish eating habits. Science of the Total Environment 1993;136(31):213-227.

23. Agency for Toxic Substances and Disease Registry (ATSDR). 1999. Toxicological profile for Mercury. Atlanta, GA: US Department of Health and Human Services, Public Health Service.

24. Skare I, Engqvist A. Human exposure to mercury and silver released from dental amalgam restorations. Archives of Environmental Health 1994;49(5):384-394.

25. Information for health care professionals mercury exposure and toxicity. OSHA-Section of Environmental Epidemiology and Toxicology. Office of Public Health, Louisiana Department of Health and Hospitals. Available at: www.seet.dh.la. Accessed on: December 2008.

26. Guidelines for identifying populations at risk from mercury exposure. United Nations Environmental program. Accessed on: August 2008. Available at: http://www.chem.unep.ch.

27. Clarkson TW. Mercury. J Am College Toxicol 1989;8(7): 1291-1296.

28. Nicolae A, Ames H, Quinonez C. Dental amalgam and urinary mercury concentrations: a descriptive study. BMC Oral Health 2013 Sep 9;13:44.

29. Olsson S, Bergman M. Daily dose calculations from measurements of intraoral mercury vapor. J Dent Res 1992;71(2): 414-423.

30. Guzzi G, Pigatto PD. Urinary mercury levels in children with amalgam fillings. Environ Health Perspect 2008 Jul; 116(7):A286-A287.

31. Xibiao Ye, Qian H, Xu P, Zhu L, Longnecker MP, Fu H. Nephrotoxicity, neurotoxicity, and mercury exposure among children with and without dental amalgam fillings. Int J Hygiene Environmental Health 2009;212(4):378-386. 